\title{
Mechanically ventilated patients in internal medicine wards: Survival and outcome one-year post-discharge
}

\author{
Bathish Jlal, Mansur Mahmud, Bozaberov Galina and Zeidman Aliza* \\ Departments of Internal Medicine B, Hasharon Hospital, Rabin Medical Center, affiliated with Sackler Faculty of Medicine, Tel Aviv University, Tel Aviv, Israel
}

\begin{abstract}
Mechanical ventilation in internal medicine wards is challenging. Weaning the patients from mechanical ventilation (MV) is an even bigger challenge. The aim of this study was to characterize the mechanically ventilated patient's population in an internal medicine ward, their weaning rate, and one-year mortality and survival rate.

Methods: The study was designed as a retrospective study. We collected and analyzed data on MV patients that were hospitalized during $2016-2017$ in Internal Medicine Department B, Hasharon Hospital, Rabin Medical Center, Israel. The data was analyzed according to age, gender, ethnicity, background diseases, functional status at admission, marital status and residence of the patient (home or nursing facility). We followed the patients for one year after first admission and analyzed survival and mortality rate, weaning rate, readmission, and reintubation rates.

Results: Data were collected from 200 computerized patient records who were ventilated and admitted to Internal Medicine Department B during 2016-2017. A significant statistical relationship was found between the age of the patients (over 75 years) and mortality after one year. There was also a significant statistical relationship between the patient's independence and residence (home or nursing facility) for the first year after intubation. Only $6 \%$ of the elderly non-ambulatory patients who came from nursing homes survived one year after discharge. No relationship was found between the patient's gender, ethnicity or marital status for survival or mortality after one year. There was also no relationship between where the intubation took place (home/hospital/ward) and survival or mortality.
\end{abstract}

Conclusions: Older MV patients coming from nursing homes and in need of nursing care had the lowest survival rates. When discussing intubation with the patient, family, medical and nursing staff and interns, these factors should be presented along with an in-depth discussion and awareness of the dying patient law.

\section{Introduction}

Mechanical ventilation (MV) in patients admitted to the internal wards poses a very complex professional, ethical and humanitarian challenge. The decision whether to ventilate any patient who is in critical condition regardless of the patient's general condition, survival chances, or prior instructions that the patient or family left, is a daily occurrence in internal medicine departments [1]. Advancements in medicine, technology and artificial respiration techniques, from the 1960 's to the present has led to an increase in the number of ventilated patients in general hospitals. Many ventilated patients in internal medicine departments are there mainly due to lack of space in intensive care units. The increase in the rate of ventilated patients is partly due to an increase in life expectancy. We see patients 100 years old and more in internal medicine wards with a plurality of chronic illnesses which requires advanced nursing care $[2,3]$. In addition, due to the hospital's heterogeneous population with different ethnic, religious and cultural backgrounds, different expectations of close family members, and the emotional difficulty of the nursing and medical staff who deal with older patients in difficult and complex conditions, makes the mater even more complex.

In the internal medicine departments, hospitalization and treatment of ventilated patients is carried out in "enhanced treatment rooms". These rooms require professional and skilled nursing staff and round the clock supervision. These conditions are not always available in internal medicine departments that have a patient load beyond the inpatient beds, a chronic shortage of physicians and nurses, staff burnout and lack of professional prestige.
In the professional literature, there are not many studies on ventilated patients in internal medicine wards. In Israel, a number of studies have been published including studies on patients who have been hospitalized and treated in intensive care units. In 1996, Shoshana Abudi et al. published a study [4] examining ventilated patients in Israeli internal medicine wards and they checked one-year morbidity, mortality and survival. Demographic variables and dependence on various comorbidities were also examined. In this study, which included 640 respiratory patients admitted to Israeli hospital internal medicine wards, it was found that only about $20 \%$ were alive after one year. The lowest survival rate was among patients with infectious diseases, sepsis and elderly patients. There was also a strong positive correlation between family and staff expectations for both survival and death. The researchers' conclusions were mainly in the ethical aspect of the medical decision-making process in terminally ill patients and in those defined as patients who are near death and to respect the patient's and family's wishes when they want only supportive care.

In 2013, Kogan et al. published a similar study [5] that was done in an internal medicine department at the Barzilai Hospital in Ashkelon. This study encompassed 97 patients over the age of 60; most of them were dependent on nursing care. The inpatient survival rate in this study was $24 \%$. The worst prognostic factors included mainly sepsis

${ }^{*}$ Correspondence to: Zeidman Aliza, Departments of Internal Medicine B, Hasharon Hospital, Rabin Medical Center, affiliated with Sackler Faculty of Medicine, Tel Aviv University, Tel Aviv, Israel, E-mail: alizaz@clalit.org.il

Received: June 09, 2020; Accepted: June 24, 2020; Published: June 29, 2020 
and infectious diseases, especially pneumonia. The conclusions in this study were also largely ethical: deciding who to ventilate, respecting the patient's and his/her family's wishes not to ventilate, and exercising senior medical judgment in patients who are near death.

Simchen et al. published a study [6] on critically ill patients admitted to intensive care units and found that there is a benefit even for short-term intensive care unit hospitalization until the patient's condition is stabilized before being transferred to internal medicine wards. The researchers concluded that more ventilated patients should be first transferred to intensive care units before being hospitalized in internal medicine wards.

In 2010, Liberman et al. [7] examined 579 ventilated patients in intensive care and internal medicine wards, and found that most of the patients in the internal medicine wards were older and more ill compared to those in the intensive care units and, accordingly, higher mortality rates were recorded in the internal medicine wards. This work also found that the lower mortality rate in intensive care units was primarily related to the patients' younger age and the characteristics of the illnesses for which they were ventilated rather than to the ICU care itself [3]. However, in lieu of advancements in medical technology, there have been no recent studies on the elderly ventilated population.

The purpose of the study: To characterize the population of inpatient ventilated patients in an internal medicine department and evaluate the course of treatment, prognostic factors for survival and mortality during hospitalization and a year later.

\section{Methods}

A retrospective study was designed for patients who were mechanically ventilated from January 2016 to December 2017 and were hospitalized in the Internal Medicine B Department at Hasharon Hospital, Rabin Medical Center in Israel. This is a community secondary hospital of 250 beds with an intensive care unit of four beds. Therefore, most of the critically ill patients were admitted to the internal medicine wards. The study group comprised of 200 patients who required mechanical ventilation upon admission to the hospital, whether in the emergency room (ER), our department or other medical wards in the hospital. However, the period of hospitalization was in the Internal Medicine B ward. We collected and analyzed data on intubation rates according to age, gender, ethnicity, comorbidities, main diagnosis, and mortality rates. Data were also collected on weaning from MV, discharge rates, and survival rates for one year after discharge. Prehospitalization status data included the patient's ambulatory status, daily living activities, residency (home or institution), chronic diseases, usage of oxygen at home and disability status in which the patients were divided into totally independent or dependent in activities of daily living (ADL). The data source was from the Chameleon and Bina database systems of Clalit Health Services in Israel. Chameleon and Bina are computerized personal file databases which integrate different data sources and provide online, history from different data sources regarding medical activities in all the Clalit Health Services systems.

\section{Statistical analysis}

Statistical analysis was performed using Microsoft Excel software (version 14). The statistical tests included a two-sample t-test assuming equal variances. In addition, a two-sided Fisher test and a chi-squared test were done for accuracy in comparative data. Probabilities with a $\mathrm{p}$ level $<0.05$ were regarded as significant.

\section{Results}

Data were collected from 200 patients who were admitted to the Internal Medicine Department between the years 2016-2017 (Table 1 ). The mean age was $79 \pm 12.8$, with the youngest age being 39 and the oldest age being 110 years. Of the 200 patients, 104 patients $(52 \%)$ were of Ashkenazi descents, including immigrants from the former Soviet Union, eighty-eight (44\%) were of Sephardi descent including countries of origin such as Morocco, Iraq, Yemen, Greece, and Turkey. Only six patients (3\%) were Arabs and two patients (1\%) had unknown origin. During the hospitalization, $54 \%$ of the patients died and $46 \%$ of the patients were discharged to their home or various institutions as described below. The follow-up of hospital records after one year of hospitalization found that the overall mortality rate increased to $89 \%$ and a total of $11 \%$ of patients survived the first year after ventilation. Metrics such as patient age, nursing status, and albumin level measured during hospitalization were of prognostic significance with statistical significance as detailed in Table 2.

An examination of where the patients were ventilated found that $8 \%$ of patients were ventilated at home (9 patients) or in an institution (7 patients) and most of the patients were ventilated in the emergency room or in another hospital ward (48\%, 96 patients), compared to $44 \%$ (88 of patients) who needed ventilation during hospitalization in the Internal Medicine Department.

When examining the major cause of hospitalization, we found that $138(69 \%)$ patients were hospitalized for respiratory problems including: pneumonia (55\%), chronic obstructive pulmonary disease (COPD, 15\%), chronic heart failure (CHF, 14\%) and only $5 \%$ of patients were hospitalized for sepsis. Three percent of the patients underwent full resuscitation while hospitalized.

Mean hemoglobin levels were around $11.9 \pm 2.68 \mathrm{~g} \%$. Mean creatinine was $1.18 \mathrm{mg} / \mathrm{dl}$ with the highest value being $4.6 \mathrm{mg} / \mathrm{dl}$. The average albumin value was $3.58 \mathrm{~g} / \mathrm{dl}$ with the minimum value being 2.2 $\mathrm{g} / \mathrm{dl}$.

Only $15 \%$ were intubated five years prior to the current hospitalization and for most of the patients $(171,85 \%)$ this was their first intubation in the last five years. Only $18 \%$ of patients underwent a

Table 1. Patients' characteristics and survival rates

\begin{tabular}{|l|c|c|c|}
\hline Characteristics & $\begin{array}{c}\text { Number of } \\
\text { patients }\end{array}$ & Percentage & $\begin{array}{c}\text { Survival rate after } \\
\text { one year }\end{array}$ \\
\hline Age & 97 & $40 \%$ & $27 \%$ \\
\hline$=<75$ & 121 & $60 \%$ & $6 \%$ \\
\hline$>75$ & \multicolumn{5}{|l|}{} \\
\hline Gender & 94 & $48 \%$ & $11 \%$ \\
\hline Male & 106 & $52 \%$ & $10 \%$ \\
\hline Female & \multicolumn{5}{|l|}{} \\
\hline Ethnicity (origin) & 88 & $44 \%$ & $11 \%$ \\
\hline Sephardic & 104 & $52 \%$ & $10 \%$ \\
\hline Ashkenazi & 2 & $1 \%$ & $16 \%$ \\
\hline Unknown & 6 & $3 \%$ & $11 \%$ \\
\hline Arabic & 84 & $42 \%$ & $7 \%$ \\
\hline Marital status & 84 & $42 \%$ & $5 \%$ \\
\hline Married & 20 & $10 \%$ & $12 \%$ \\
\hline Widower & 12 & $6 \%$ & $12 \%$ \\
\hline Single & 108 & $54 \%$ & $9 \%$ \\
\hline Divorced & 92 & $46 \%$ & \\
\hline Residence at time of admission & & \\
\hline Home & & & \\
\hline Nursing home & & & \\
\hline
\end{tabular}


Table 2. Comparison of characteristics and survival rates after one year

\begin{tabular}{|c|c|c|c|c|}
\hline Effect & Odds Ratio Estimate & $\begin{array}{l}\text { Lower } 95 \% \text { Confidence } \\
\text { Limit for Odds Ratio }\end{array}$ & $\begin{array}{l}\text { Upper } 95 \% \text { Confidence } \\
\text { Limit for Odds Ratio }\end{array}$ & Pr $>$ Chi-Square \\
\hline Gender male vs female & 0.790 & 0.324 & 1.926 & 0.6041 \\
\hline Marital status Married vs Divorced or widowed & 1.589 & 0.220 & 11.504 & 0.6465 \\
\hline $\begin{array}{l}\text { Functional status Independent } \\
\text { vs Dependent }\end{array}$ & 7.261 & 2.721 & 19.378 & $<.0001$ \\
\hline Age & 1.066 & 1.032 & 1.101 & 0.0001 \\
\hline Ethnicity Arab & 1.233 & 0.009 & 168.830 & 0.9334 \\
\hline Ethnicity Ashkenazi & 3.059 & 0.032 & 292.803 & 0.6309 \\
\hline Ethnicity Sephardi & 2.515 & 0.026 & 240.934 & 0.6920 \\
\hline Reason for intubation SEPSIS & 4.204 & 0.036 & 491.651 & 0.5545 \\
\hline Reason for intubation pneumonia & 2.736 & 0.062 & 121.263 & 0.6029 \\
\hline Reason for intubation after resus & 2.602 & 0.020 & 330.759 & 0.6989 \\
\hline Reason for intubation CHF & 0.855 & 0.018 & 39.629 & 0.9363 \\
\hline Reason for intubation COPD & 0.530 & 0.012 & 23.763 & 0.7434 \\
\hline Site of intubation Emergency vs Department & 1.108 & 0.425 & 2.893 & 0.8337 \\
\hline Site of intubation Home vs Department & 0.497 & 0.127 & 1.942 & 0.3149 \\
\hline Accommodation institute vs home & 3.679 & 1.247 & 10.855 & 0.0183 \\
\hline oxygen YES vs NO & 0.661 & 0.232 & 1.886 & 0.4390 \\
\hline Intubation in the last 5 years & 0.473 & 0.162 & 1.377 & 0.1697 \\
\hline Discharge institute vs home & 2.609 & 0.997 & 6.828 & 0.0507 \\
\hline Tracheostomy YES vs NO & 0.487 & 0.178 & 1.331 & 0.1604 \\
\hline Extubation during hospitalization & 0.063 & 0.012 & 0.344 & 0.0014 \\
\hline Reintubation in 5 years & 0.473 & 0.162 & 1.377 & 0.1697 \\
\hline Hemoglobin & 0.875 & 0.705 & 1.085 & 0.2231 \\
\hline Creatinine & 1.667 & 0.865 & 3.210 & 0.1266 \\
\hline Albumin & 0.452 & 0.211 & 0.971 & 0.0419 \\
\hline
\end{tabular}

tracheostomy after intubation versus $82 \%$ (164) of patients who did not undergo this procedure during their hospitalization.

Of the patients who did not undergo tracheostomy during hospitalization, extubation was performed in $52 \%$ of patients compared to $48 \%$ who were unable to remove the ventilation tube during hospitalization. Repeat intubation was performed in 13 patients (7\%) whose ventilation tube was removed.

Of the 200 patients who participated in the study, 92 patients (46\%) were discharged from the department, most (70\%) to various institutions and 30\% were discharged to their home. The other 108 patients died (54\%) during hospitalization, with the primary cause of death being sepsis and pneumonia.

When examining prognostic values and their relationship to mortality and survival after one year (Table 3), we found that age had a significant effect $(\mathrm{p}<0.0001)$. As the age of the patients rose, their first-year survival rates decreased. It was also found that the patient's baseline functional status upon admission to the ward was statistically significant for survival. There was a strong correlation between the lack of independence and lower one-year survival rate $(\mathrm{p}<0.0014)$. Other statistically significant factors included the patient's place of residence prior to hospitalization. Patients who did not live at home had lower survival rates $(\mathrm{p}<0.0183)$. Patients who were ventilated during their entire hospitalization and were not extubated, had lower survival rates a year after their hospitalization $(\mathrm{p}<0.0014)$. In addition, low albumin levels (lower than $3.5 \mathrm{~g} / \mathrm{dL}$ ) during hospitalization had a borderline statistical significance of $\mathrm{p}<0.0410$.

The patient's gender and origin had no prognostic significance. There was also no significance between where the patient was intubated (home, institution, or ward) and survival chances $(\mathrm{P}>0.6)$. No significance was found between the marital status of the patient and
Table 3. Relationship between the patients' indices and survival after one year

\begin{tabular}{|c|c|c|c|}
\hline & $\begin{array}{c}\text { Alive after 1 } \\
\text { year }\end{array}$ & $\begin{array}{c}\text { Dead after 1 } \\
\text { year }\end{array}$ & p \\
\hline Num of Patients (200) & 21 & 179 & \\
\hline$\%$ Male/Female & $53 \% / 48 \%$ & $47 \% / 52 \%$ & NS \\
\hline Age & $68.3 \pm 11$ & $81.3 \pm 9.4$ & $<\mathbf{0 . 0 0 0 1}$ \\
\hline Dependent & $25 \%$ & $75 \%$ & $<\mathbf{0 . 0 0 0 1}$ \\
\hline Institute/home & $5 \% / 19 \%$ & $95 \% / 81 \%$ & $<\mathbf{0 . 0 1 8 3}$ \\
\hline$\%$ extubation/no extubation & $20 \% / 1 \%$ & $80 \% / 99 \%$ & $\mathbf{0 . 0 0 1 4}$ \\
\hline Sephardic /Ashkenazi origin & $11 \% / 9 \%$ & $89 \% / 91 \%$ & NS \\
\hline $\begin{array}{c}\text { Respiratory/other causes for } \\
\text { intubation }\end{array}$ & $21 \% / 9 \%$ & $79 \% / 91$ & $\mathbf{0 . 0 0 1 4 3}$ \\
\hline Albumin & $21 \%$ & $79 \%$ & $\mathbf{0 . 0 0 4 1}$ \\
\hline
\end{tabular}

survival rates. The survival rates were similar in married, widowed, or singles $(\mathrm{P}>0.646)$. Additional metrics such as the need of oxygen pre-hospitalization $(\mathrm{P}>0.436)$, intubation history over the past five years $(\mathrm{P}>0.146)$, and hemoglobin levels $(\mathrm{P}>0.223)$ had no statistical prognostic significance.

\section{Discussion}

In recent years, the number of people ventilated in the internal medicine wards in Israel is on the rise, with many patients admitted to the internal medicine wards in the context of increased intensive care. The decision of who and when to ventilate assumes ethical and moral dimensions when we review the non-optimistic results of the few studies conducted on this patient population in Israel and internationally.

It seems that, despite technological advances, the numbers of ventilated patients are increasing every year and the need for inpatient respiratory beds is also rising. In the Internal Medicine Department B of Hasharon Hospital, four beds have been added in recent years for a total 
of eight beds in two rooms which are called increased treatment rooms. All of this was done without increasing the number of staff doctors and nurses. The load in the winter months is maximal and the burden on the medical and nursing staff is increasing. We are well aware of the dying patient law [8] and in most cases, we endeavor to initiate and coordinate expectations with the patient and the patient's family prior to intubation. However, sometimes patients arrive in critical condition and the decision has to be made immediately and if there are no prior instructions or no immediate family members available, the patient will be intubated. In addition, some patients have been already intubated in their place of residence, emergency room, or other hospital department and are transferred to the ward already intubated. Therefore, we do not always have control over the decision to intubate a patient.

In this retrospective study, we attempted to characterize the group of patients who were admitted to our internal medicine ward in terms of demographics, reasons for ventilation, where the patient was ventilated, the patient's ambulatory status and accompanying illnesses, and finally, post-hospital survival rates one year later. Our findings show that the survival rates and release from hospitalization rates of our patients were similar and even higher than other studies conducted in Israel in other internal medicine departments [5-7]. Our discharge rate was $46 \%$ compared to $29 \%$ for Kogan et al. [5]. However, the survival rate after one year was very low and only $11 \%$ of the patients survived after one year. We found no recent study examining survival rates after one year of being discharged from an internal medicine ward. In studies done on patients after hospitalization in intensive care units, the survival rate is about $20 \%$ a year later. However, the patient age in these studies is much younger (mean age 60). Statistically significant predictors of patient survival after one year are similar to other previously published studies $[5,9]$. The patient's age has a clear and significant effect, in that as the patient ages, the lower the chances of survival. In addition, there is no clear indication as to who is considered old. Some studies define old as being older than 60 years of age and in some studies, it was 80 years or older [4-7]. In our study, elderly patients were defined as 75 years or older and it was a clear predictor of mortality. A literature review of the patient's ambulatory status at the time of hospitalization and its impact on patient survival did not find many references from studies around the world. In 2013, Kogan et al. published a study conducted at Ashkelon's Barzilai Medical Center where they too found a clear link between the patient's functioning level and mortality [5] as we found in our study.

The patients' level of functioning during hospitalization and postdischarge, had a pronounced effect, as also seen in previous studies $[5,9]$. If patients were dependent on nursing care or came from a nursing care facility, they had a significantly lower survival rate of $9 \%$ compared to a $12 \%$ survival rate in independent home-based patients after one year. When we examined other variables and examined only patients older than 75 years who came from nursing homes, survival rates dropped to only $6 \%$ which means that $94 \%$ of this population died within a year of hospitalization. Examining the major causes for ventilation found that most had respiratory difficulties due to pneumonia (55\%), heart failure (14\%) or a worsening of a known chronic lung disease (15\%). Unlike other studies that demonstrated a significant statistical relationship between sepsis and mortality rates [7,9] in this population, we did not find sepsis to be a significant factor. This might be due to the rates of sepsis as a cause of respiration being very low (5\% of all patients). Lieberman et al. [7] found statistical significance in the association between renal failure and mortality. We examined the association between hemoglobin, albumin, and creatinine at the time of hospitalization and survival and found that only low albumin levels had a significant statistical association with mortality. Hemoglobin and creatinine levels at the time of hospitalization had no effect on mortality or survival rates. The difference may be because we examined creatinine levels at hospitalization admission while Lieberman's study also referred to renal failure that occurred during hospitalization, possibly as an expression of multiple organ failure and morbidity. There was no association between patient gender, ethnicity or marital status at the time of hospitalization and mortality or survival rates and we could not find any other studies that examined these variables.

\section{Conclusion}

When discussing mechanically ventilated patients who are admitted to an internal medicine department or who require intubation when in the internal medicine ward, a number of factors should be considered that can influence patient survival. These include the patient's age, condition, and if the patient came from home or a nursing facility. Patients older than 75 years, who come from a nursing home, have a one-year survival rate of $6 \%$.

It is necessary to raise and discuss the dying patient law [8] and to define an end stage patient to the staff on a daily basis and to discuss this with the patient's family before intubation with much sensitivity and dignity while presenting the facts and chances of survival.

In light of our findings, further research is needed involving multiple centers and a large number of internal medicine wards to further study this specific growing population of patients.

\section{References}

1. Beddel SE, Delbanco TL, Cook EF, Epstein FH (1983) Survival after CPR in the hospital. N Eng J Med 309: 569-576. [Crossref]

2. Eduard SB (1993) When the physician won't give up. AJN 93: 34-37.

3. Longstreth JR (1990) Does age affectoutcomes of out of hospital CPR. JAMA 264: 2109-2110.

4. Abdi SH, Redler A, Katz A, Gabay A (1996) The dilemma of resuscitation and mechanical ventilation the in the internal medicine. Medicine and Law 96: 67-76.

5. Kogan J, Rodnicki A, Cohen A (2016) The treatment of Mechanically ventilated patients in internal medicine wards. Medicine 2016: 482-484.

6. Simchen E, Sprung CL, Galai N, Gurevich YZ, Lavi YB, et al. (2007) Survival of critically ill patient hospilalized in and out of intensive care. Crit Care Med 35: 449457. [Crossref]

7. Lieberman D, Nchshon L, Miloolavsky O, Shimoni A, Zelinger J, et al. (2010) Elderly patients undergoing mechanical ventilation in and out of intensive care units: a comperative prospective study of 579 ventilations. Crit Care 14: R48. [Crossref]

8. Medical administration, center for preliminary medical Guidelines. The patient law tends to die. Ministry of Health Israel. 2005.

9. Roupie E, Lepage E, Wysocki M, Fagon JY, Chastre J, et al. (1999) Prevalence, etiologies and outcome of the acute respiratory distress syndrome among hypoxemic ventilated patients. Intensive Car Med 25: 920-929. [Crossref]

Copyright: (C2020 Jlal B. This is an open-access article distributed under the terms of the Creative Commons Attribution License, which permits unrestricted use, distribution, and reproduction in any medium, provided the original author and source are credited. 